\title{
Red Meat Production Forecast and Policy Recommendations in Line with 2023 Targets in
}

\author{
Sevim AKGÜL, PhD \\ Bayburt Üniversitesi, İ̈BF-Iktisat Bölümü, akgul@bayburt. edu. tr \\ Şaduman YILDIZ, PhD \\ Bayburt Üniversitesi, İ̈BF-iktisat Bölümü, sayildiz@bayburt. edu. tr
}

\begin{abstract}
There is a certain delay between the manufacturers due to red meat production decisions, give producers in price compared to the previous year, the production decision, this situation leads to a surge in the amount of consumption of red meat and red meat prices. Individuals in a balanced diet, especially red meat consumption, are considered to be of great importance to supply and economic development criteria. An economic variable values will be in the future, according to the cyclical state of the economy, always involves uncertainty. This uncertainty also applies to the red meat production. In this study, consumption of red meat to Turkey for estimation, Box-Jenkins forecasting models are used. Between the years 2016-2023 red meat production forecasts are made regarding Turkey in the framework of this model. In line with the objectives of 2023 , Turkey to increase the consumption of red meat, is given to policy proposals.
\end{abstract}

Keywords: Turkey's Red Meat Production, Box-Jenkins Model

\section{Introduction}

A balanced diet, all sorts of nutrients the body needs to consume enough. The foods including vegetable and animal foods are divided into two main groups, especially red meat consumption of animal foods, balanced diet and is of great importance for human health. In fact, the annual per capita meat consumption in the country is considered as a development criterion.

Turkey is a country with geography and climatic conditions suitable for the production of red meat. However, the livestock farming sector, particularly in support always remained in the background. The share of animal husbandry in agricultural production in most developed countries is over 50\%. In Turkey, this ratio is around 25\% (Ören, Bahadır, 2005:1).

Until the 1980s, the existence of very advanced and animal husbandry in Turkey has increased steadily. However, after the 1980s, the wrong agricultural policy and began to decline with the increase in the cost of livestock sector. Since 2000, however, thanks to state support and incentives has been a considerable increase in the number of large-scale breeding facilities (Livestock Sector Report, 2013: 14).

"In the 2000s "Agricultural Reform Implementation Project" has been radical changes in agricultural policy. During this period, Turkey solve the problems found in the animal and to develop the livestock sector, Agriculture and Rural Affairs Ministry prepared and will support program covering the years 2000-2004 "About Animal Supporting The Decree" was put into practice. With the start of EU negotiations study Turkish livestock sector is considered a strategic approach. In order to establish a strong structure of the livestock sector "Livestock Master Plan and Strategy for 2005-2013" has been prepared. About Supporting Animal Ministerial Decree (2005/8503) 24/02/2005, published in Official Gazette numbered 25737 and entered into force. With strategy, goals and livestock support tools have been put forward. It will be implemented with the support of the livestock sub-sector, intended to increase the number of specialized livestock operations ( Anonim, 2011:12). 
On 24 January 1980, meat and animal products are excluded from the scope in order to support economic measures. Partially 1992 meat and fish Institution (MKI), Turkey Milk Industry Association (MIA) and Feed Industry (FEEM-IND) is fully customizable. On April 5, 1994 economic stabilization program began to be implemented. In March 1996, it appeared Mad Cow Disease. It has experienced an economic crisis in 2001. On 30 April 2010 it was allowed to import. All these developments have affected the livestock sector negatively (Aydın et al., 2011:5).

Red meat production is mainly mountainous cattle and ovine in Turkey. Red meat; cattle are mainly of cattle and Buffalo is derived from. Still red meat; small cattle is of is obtained from sheep and goats. The following Table 1. Turkey red meat production numbers are given according to animal species. Referring to Table 1. buffalo meat production has shown a downward trend from 1991 until 2015. Beef production increased nearly 3 times. Goat meat production has increased by about 1.5 times. The mutton production declined approximately 1.3.

Table 1: Turkey Meat Production (1991-2015) (Tons)

\begin{tabular}{|l|l|l|l|l|l|}
\hline Year & Sheep & Goats & Cattle & Buffaloes & Total Meat Production \\
\hline 1991 & 128626 & 19570 & 309563 & 8803 & 466562 \\
\hline 1995 & 102115 & 14124 & 292447 & 6095 & 414781 \\
\hline 2000 & 111139 & 21395 & 354636 & 4047 & 491217 \\
\hline 2005 & 73743 & 12390 & 321681 & 1577 & 409391 \\
\hline 2010 & 135687 & 23060 & 618584 & 3387 & 780718 \\
\hline 2.011 & 107076 & 23318 & 644906 & 1615 & 776915 \\
\hline 2012 & 97334 & 17430 & 799344 & 1736 & 915844 \\
\hline 2013 & 102943 & 23554 & 869292 & 366 & 996155 \\
\hline 2014 & 98978 & 26770 & 881999 & 526 & 1008273 \\
\hline 2015 & 100021 & 33990 & 1014926 & 326 & 1149263 \\
\hline
\end{tabular}

Source: TUIK

"Considering supports livestock being implemented in Turkey; the share of support farming supports about $15 \%$ of the total. In recent years, the increase in the share of total support and that support livestock varied supports applied, is remarkable. the highest share in the support for livestock, fodder plants is about 50\% ( Anonim, 2011:12).

Red meat prices in Turkey; It is influenced by several factors directly or indirectly. Direct related factors; feed material, feed and labor expenses. Factors affecting indirectly; animal species, substitute products (sheep and goat meat, beef) prices, import or export status, the presence of state intervention, livestock support, interest rates, instability in milk prices, consumer demand, consumer preferences (Cevger and Sakarya, 2006:1).

The economic crisis and the measures taken place in Turkey; Red meat prices negatively affected. Stopping the import of animals and increasing amounts of red meat production; Turkey will make the red meat prices remain stable. The following Table 2 shows the red meat prices in Turkey according to animal species.

\section{Table 2: Turkey Meat Prices (1994-2014) (kg/TL)}

\begin{tabular}{|l|l|l|l|l|}
\hline Year & Mutton Prices & Goat Meat Prices & Beef Price & Buffalo Meat Price \\
\hline 1994 & 0,14 & 0,13 & 0,15 & 0,14 \\
\hline 1995 & 0,29 & 0,27 & 0,30 & 0,28 \\
\hline 2000 & 2,81 & 2,64 & 2,84 & 2,59 \\
\hline 2005 & 9,57 & 9,07 & 9,56 & 8,44 \\
\hline 2010 & 18,93 & 18,32 & 18,41 & 16,65 \\
\hline 2011 & 20,36 & 18,87 & 18,54 & 16,8 \\
\hline 2012 & 19,64 & 18,78 & 17,51 & 15,97 \\
\hline 2013 & 18,14 & 17,00 & 15,83 & 15,57 \\
\hline 2014 & 18,28 & 17,00 & 17,10 & 15,25 \\
\hline
\end{tabular}

Source: TUIK 
First objective of the study is to make Turkey the 2015-2023 period meat production forecasts. The second objective is in line with its targets in 2023, Turkey decided to place the policy recommendations for increasing the production of red meat.

\section{Literature review}

In the world and Turkey, there are studies on red meat production estimate. Günaydın G., (2007) works; European Union accession process of Turkey has tried to analyze the potential impact on the livestock sector under various future predictions (Günaydın, 2007). Koç A. A. (1995) works; for supply of red meat derived from cattle and sheep for Turkey it has established a separate supply models (Koç, 1995). Yavuz F., Zulauf C. R., (2001) works; the actual amount of red meat production forecast based on the assumption that Turkey is far below, have developed a method to predict (Yavuz ve Zulauf, 2001). Dastagiri (2004) works; delayed models using animal products has made the supply and demand forecasts until 2020 under different scenarios (Dastagırı, 2004). Çelik Ş., (2012) works; Turkey's 1936-2011 forecasts made by red meat production data with the Box-Jenkins method until 2020 (Çelik, 2012).

\section{Methodology}

In this study; Time series analysis method is used. A variable values occur in the observation time of the event or the object, are the time series. Time series analysis methods to build statistical models using historical values and estimates of future observations with this model (lhaka, 2006:1).

One of the methods commonly used in time series analysis method is the Box-Jenkins. Box-Jenkins method; It is applied to the discrete and linear stochastic processes. The basis of this method is based on the paradigm of ARIMA. Method to get a stable result of whether or general acceptance, recognition possibility to model any time you include or not include seasonal series elements and is easily implemented with the help of an econometric software package (Maddala, 1998:17).

Auto Regressive (AR), Moving Average (MA), Autoregressive-Moving Average (ARMA) and Autoregressive Integrated Moving Average (ARIMA) are Box-Jenkins prediction models. AR (p), MA (q) and combinations thereof, which ARMA ( $p$, q) models were applied to stationary processes, ARIMA ( $p, d, q)$ models are applied to non-stationary process.

The stationary time series; mean and variance does not change over time. Covariance between the two periods; This covariance are not calculated in the period depends on the distance between the two periods only.

$$
\begin{aligned}
& \text { Average }=E\left(Y_{t}\right)=\mu \\
& \text { Variance }=\operatorname{var}\left(Y_{t}-\mu\right)^{2}=\delta^{2} \\
& \text { Covariance }=X_{k}=E\left(\left(Y_{t}-\mu\right)\left(Y_{t-k}-\mu\right)\right)
\end{aligned}
$$

ARIMA ( $p, d, q)$ Models: When stationary time series; AR (p), MA (q) and ARMA $(p, q)$ which is available to suit the model. But in real life, most of the time series is non-stationary (Sevüktekin and Nargeleçekenler, 2010:173). Immobilized to the non-stationary time series, which is made by taking the difference. In this case the model, ARIMA (p,d,q) is expressed. "d" is the series stabilizing parameters, that is the differentiation parameter (Brooks, 2008: 233).

\section{Analysis}

In this part of the study, between the years 1994-2015, the Turkey meat production, with time series analysis, predictive values were obtained until 2023. Using Box-Jenkins methods, modeling was conducted. Time series analysis application for, Eviews software package is used. Variable graph was drawn to start the analysis. 


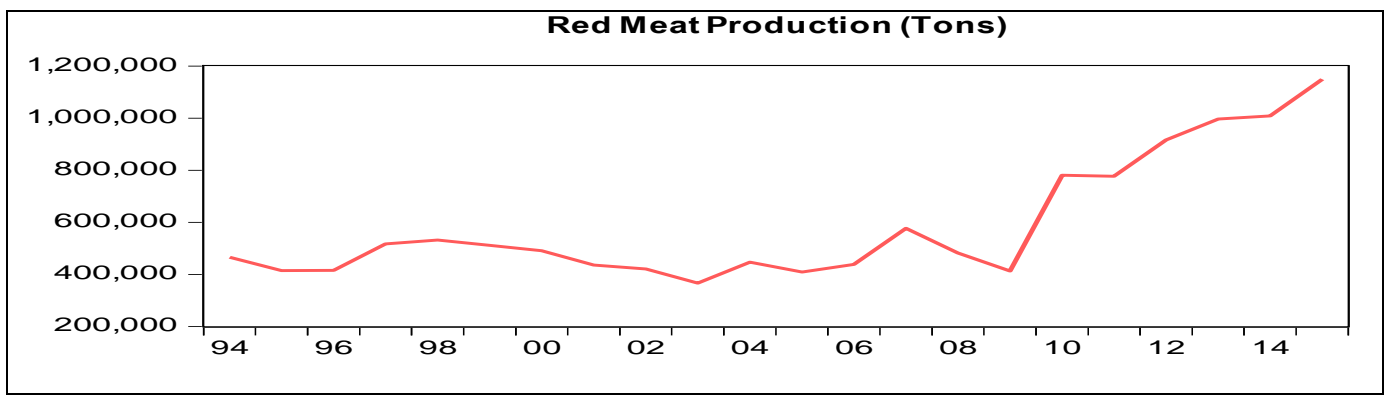

Figure 1: Movement of the Red Meat Production Series

Time series is not stationary, it was immobilized for taking the difference of the first degree. Unit root test is done to look at the stability of the statistical time series. According to the table, because it is smaller than the critical value for the ADF test statistics, the series does not contain unit roots. That series is stationary.

\section{Table 3: Unit Root Test Results of DE Series}

Null Hypothesis: DE has a unit root

Exogenous: Constant

Lag Length: 0 (Automatic - based on AIC, maxlag=4)

\begin{tabular}{llll}
\hline \hline & t-Statistic & Prob. $^{*}$ \\
\hline \hline Augmented Dickey-Fuller test statistic & & \\
\hline Test critical values: & $1 \%$ level & -5.093083 & 0.0006 \\
& $5 \%$ level & -3.808546 & \\
& $10 \%$ level & -3.020686 & \\
& & -2.650413 & \\
\hline \hline
\end{tabular}

To determine the stability of the series, it is moved to the stage of determining the most appropriate model. Because it has a linear train of red meat production series, ARIMA $(0,1,1)$ model was preferred. The estimation results are given in Table 5.

Tablo 4: ARIMA (p, 1, q) Model Selection

\begin{tabular}{|l|l|l|l|}
\hline & Akaike & Schwarz & Hannan-Quin \\
\hline Constant & ARIMA $(0,1,0)$ & ARIMA $(1,1,2)$ & ARIMA $(1,1,2)$ \\
& 26.07939 & 26.07673 & 25.90615 \\
\hline \multirow{3}{*}{ Constant+ trends } & ARIMA $(0,1,1)$ & ARIMA $(0,1,1)$ & ARIMA $(0,1,1)$ \\
\hline
\end{tabular}


Tablo 5: ARIMA $(0,1,1)$ Model Forecast

Dependent Variable: $\mathrm{D}(\mathrm{E})$

Method: Least Squares

Date: 03/02/16 Time: 21:41

Sample: 19972015

Included observations: 19

Failure to improve SSR after 16 iterations

MA Backcast: 1996

\begin{tabular}{|c|c|c|c|c|}
\hline Variable & Coefficient & Std. Error & t-Statistic & Prob. \\
\hline C & -89160.01 & 17212. 30 & -5.180016 & 0.0001 \\
\hline @TREND & 9809.626 & 1195. 264 & 8. 207077 & 0.0000 \\
\hline $\mathrm{MA}(1)$ & -0.999890 & 0.184244 & -5.426979 & 0.0001 \\
\hline R-squared & 0.593588 & \multicolumn{2}{|c|}{ Mean dependent var } & 38626.00 \\
\hline Adjusted R-squared & 0.542787 & \multicolumn{2}{|c|}{ S. D. dependent var } & 108570.9 \\
\hline S. E. of regression & 73412.95 & \multicolumn{2}{|c|}{ Akaike info criterion } & 25. 38953 \\
\hline Sum squared resid & 8. $62 E+10$ & \multicolumn{2}{|c|}{ Schwarz criterion } & 25.53865 \\
\hline Log likelihood & -238.2005 & \multicolumn{2}{|c|}{ Hannan-Quinn criter. } & 25.41476 \\
\hline F-statistic & 11. 68448 & \multirow{2}{*}{\multicolumn{2}{|c|}{ Durbin-Watson stat }} & 2. 007102 \\
\hline Prob(F-statistic) & 0.000744 & & & \\
\hline
\end{tabular}

Inverted MA Roots

1. 00

Before the prediction phase, autocorrelation and heteroscedasticity tests are performed. According to the autocorrelation of the test results is not a problem of autocorrelation in the error term, it is seen. Changing according to the variance test, that there is heteroscedasticity problem has been observed. 1994 - 2015 were estimated for the original series and is shown in Figure 2. 2016-2023 term prediction series is shown in Figure 3. Red meat production forecasts and the actual series, as shown in Figure 4.

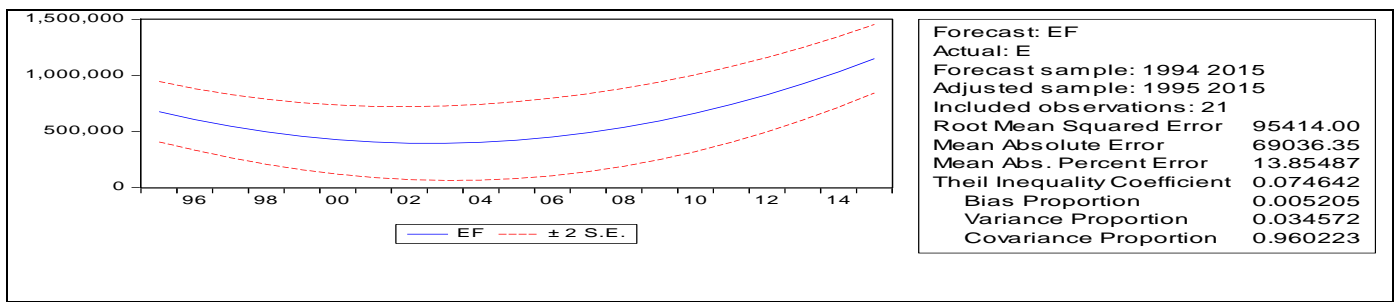


Figure 2: Red Meat Production Forecast Original Series

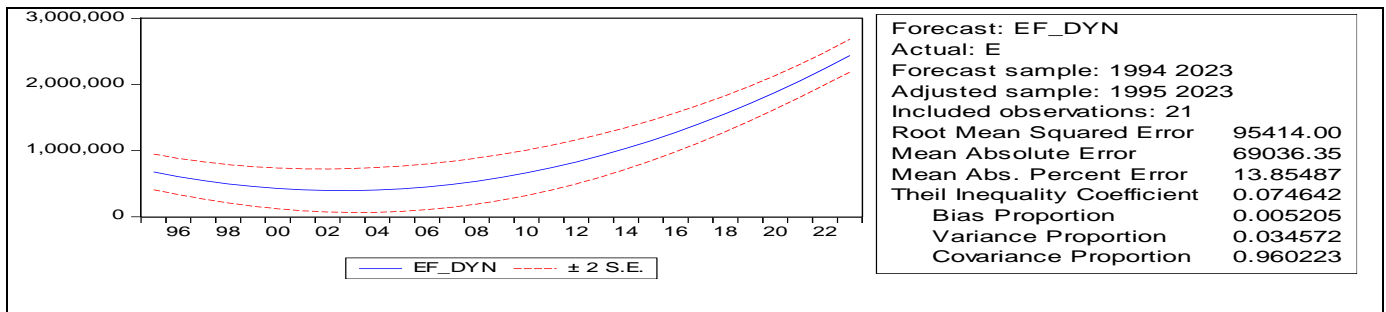

Figure 3: Red Meat Production Forecast Series

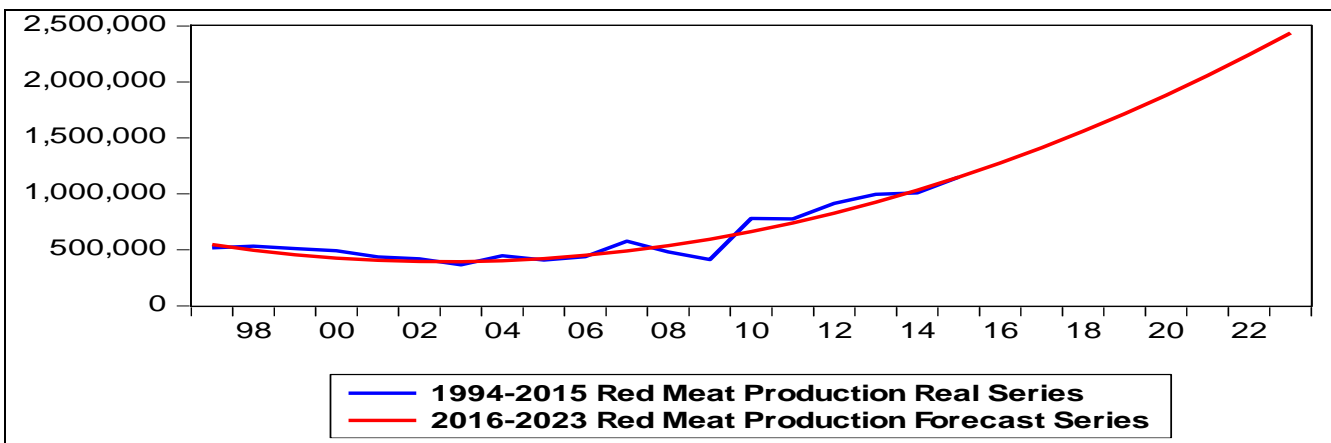

Figure 4: Red Meat Production Facts and Projections Series

\section{Conclusions}

In this study, the 2016-2023 period of Turkey red meat production predictions were made by analysis of time series. A graph of the variables are obtained. For the unit root test, generalized Dickey- Fuller (ADF) test and the Phillips-Perron (PP) test was used, it was taken into stasis. The first differences of the series, has become stagnant. The correlation of variables (ACF) and autocorrelation (PACF) graphs have been obtained. Akaike information criterion (AIC) and Schwarz information criterion (SC), the smallest of such information criterion, ARIMA $(0,1,1)$ model, has been identified as the most suitable model. Turkey for the period 2016-2023 the predictive value of red meat production was obtained. The results obtained from this study, 8-year predictive values are given in the table below. Red meat production, as seen in the Table 6 , in line with the 2023 targets will continue to increase as.

Tablo : 6 Red Meat Production Forecast Values (2016-2023) (Tons)

\begin{tabular}{|l|l|l|l|l|l|l|l|l|}
\hline Year & 2016 & 2017 & 2018 & 2019 & 2020 & 2021 & 2022 & 2023 \\
\hline $\begin{array}{l}\text { ForecastinV } \\
\text { alues }\end{array}$ & $\begin{array}{l}127583 \\
5\end{array}$ & 141229 & 155856 & $\begin{array}{l}171464 \\
8\end{array}$ & $\begin{array}{l}188053 \\
8\end{array}$ & $\begin{array}{l}205623 \\
8\end{array}$ & $\begin{array}{l}224174 \\
8\end{array}$ & 243706 \\
7
\end{tabular}

\section{Policy Recommendations}

Turkey's 2023 target is composed of 63 items. 6 of these substances covers economic goals. Reduced to 5 percent unemployment, Of interregional disparities, be reduced to an acceptable level, The eradication of poverty and to minimize the imbalance in income distribution, The participation of women in the labor force, 38 percent of the removal, 15 thousand 
disabled people receiving public and Informal employment, be reduced to 15 percent. In short, Turkey in 2023, is one of the world's most powerful 10 economies aims. And in this respect Turkey is trying to reach an average annual per capita meat consumption in developed countries. Turkey In order to meet that target, to focus on red meat production is necessary. Measures to be taken in this regard can be listed as follows.

1. Animal breeds breeding, since there is at the desired level, animal production efficiency, decreases. Breeding work should be brought into a State policy. Ministry of Agriculture, Industry Organizations and Universities to collaborate should be provided (Türkyılmaz, 2010:85-86).

2. Due to rising production costs, the number of cattle and sheep in Turkey has decreased significantly. Therefore, emphasis must be placed on feed costs. In particular, for the further deduction of feed costs, urgent measures should be taken. Businesses should be able to produce their own oath, to make silage, it must be provided (Gözener, Sayll, 2015:298).

3. Increased in recent years, the number of animals on the run. Not subjected to any control, such animals causes a significant reduction of the number of animals and animal disease increased. Food, Agriculture and Livestock Ministry by, No. 2015/04 Combating Animal Disease Control and Animal Movement Circular was issued. This circular should be applied rigorously.

4. To combat animal diseases, veterinary services should be expanded first. Vaccination programs should be organized. In particular, the spread of disease areas, should be determined. These animals should be kept under quarantine or should be culled. The cost of these animals must be paid timely and fully (Türkyılmaz, 2010:85-86).

5. Animal production in Turkey, based on the document, a system of incentives based on different regions, are implemented. In incentives for the agricultural sector, the share allocated to the livestock sector is quite high. Enough to take advantage of these incentives should be given to training activities (Mustafa Kaymakçı et al, 2000:780).

\section{References}

Anonymous, Red Meat Policy - Policy Analysis of the Government, Prime Minister's Working Group, Ankara, 2011, Livestock Sector Report 2013.

Badi H. Baltagi, Econometrics, Fourth Edition, 2008, Springer-Verlag Berlin Heidelberg.

Bilge Gozener, Murat Sayili " In Tokat City Turhal Town Production Cost in Cattle Fattening and the Factors affecting live weight gain ", Journal of Agricultural Sciences, 21 (2015): 288-299.

Celik S., (2012), "Modeling With the Box-Jenkins Method of Turkey's Red Meat Production and Production Projection" Animal Production 53 (2): 32-39, 2012

Cevger Y., Sakarya E., (2006), "Meat Prices and Factors Affecting Them in Turkey", Turk J Vet Anim Sci, 30(1), 1-6.

Chris Brooks, Introductory Econometrics for Finance, Second Edition, Cambridge University Press, 2008.

Dastagırı, M. B., 2004. "Demand And Supply Projections For Livestock Products İn India" Policy Paper 21, Nat lonal Centre For Agrıcultural Economıcs And Polıcy Research (Icar) New Delhı, Indıa. 2004.

Erol Aydin et al (2011), " in Last 25 Year in Turkey Red meat prices Changes and Analysis of Effects of Import Decision", Journal of Veterinary Medical Association, 82 (1): 3-13.

G. S. Maddala, In-Moo Kim, Unit roots, cointegration, and structural change, Cambridge University Press, 1998.

Gunaydin, G., 2007, The State of Turkey Animal in the European Union Process, 5. The National Animal Science Congress Report, 5-8 September 2007, Van. 
Koç, A., 1995, Econometric Analysis of Supply and Demand of Red Meat in Turkey and Investigation of the Red Meat Industry Structure and Functioning, PhD Thesis, Cukurova University, Adana, 1995.

Livestock Sector Report, 2013.

M. Kenan Turkyilmaz (2010), "Meat Production and Problems in Turkey", Kocatepe Veterinary Journal (2010) 3 (2): 83-90.

Mustafa Kaymakçi and others (2000), "Small Livestock Production in Turkey", Agriculture Engineering, V. Technical Conference 17-21 January, Ankara.

Mustafa Sevüktekin, Mehmet Nargeleçekenler, Ekonometrik Zaman Serileri Analizi, 3. Baskı, 2010.

Oren, N., M. and B. Bahadir., 2005. "Animal Product Policies in OECD Countries and Turkey and Emerging Transfers in Results of This Policy Results ", Animal Production 46 (1): 1-7

Ross Ihaka, Time Series Analysis Lecture Notes for 475. 726, Statistics DepartmentvUniversity of Auckland, 2006.

Yavuz F., Zulauf C. R., 2001, Introducing A New Approach To Estimating Red Meat Production In Turkey, Turkish Journal of Veterinary and Animal Sciences, 2004/4. 